\title{
CHARITÉ
}

UNIVERSITÄTSMEDIZIN BERLIN

\section{Animal Models: Value and Translational Potency}

Philipp Mergenthaler, Andreas Meisel

\section{Document type}

Book Chapter

This version is available at

https://doi.org/10.17169/refubium-31114

\section{Citation details}

Mergenthaler P, Meisel A. Animal Models: Value and Translational Potency. In: Wehling, M. (ed.) Principles of Translational Science in Medicine - From Bench to Bedside. 3rd ed. London, United Kingdom: Academic Press; 2021. p. 95-103. DOI: 10.1016/B978-0-12-820493-1.00028-3

\section{Terms of use}

All rights reserved. This document is intended solely for personal, non-commercial use. 


\section{Animal Models: Value and Translational Potency}

Philipp Mergenthaler and Andreas Meisel

Department of Experimental Neurology, Department of Neurology, Center for Stroke Research Berlin, NeuroCure Clinical Research Center, Charité Universitätsmedizin Berlin, Charitéplatz 1, 10098 Berlin, Germany.

Berlin Institute of Health, 10178 Berlin

* Correspondence: Philipp Mergenthaler (philipp.mergenthaler@charite.de) or Andreas Meisel (andreas.meisel@charite.de) 


\begin{abstract}
Modern biomedical research with the aim of translating research findings into novel therapies to benefit patients relies to a large extent on animal models of human pathophysiology. However, success stories of translational research - i.e. preclinical research that successfully predicts positive outcome of a clinical trial - are scarce. Here, we therefore address the current state of preclinical disease modeling as well as actions that have been taken to improve the translational value of animal models.
\end{abstract}

\title{
Keywords
}

Animal models, pathophysiology, disease mechanisms, preclinical randomized controlled trials, modeling of care 


\subsubsection{What is the value of animal models? - Pathophysiological concepts}

The majority of translational research relies on preclinical animal models. However, given an incredible number of examples of failed translation, i.e. phase II or phase III clinical trials, which were not able to reproduce the beneficial effect of preclinical findings (O'Collins et al, 2006; Perrin, 2014; Prinz et al, 2011), the translational value of animal models has been questioned. In particular rodent models have been accused of falsely modeling human disease conditions.

Nonetheless, many animal models are geared to replicate pathophysiological conditions found in patients. An ideal animal model of a human disease is characterized by similarities between both in terms of 1) pathophysiology, 2) phenotypical and histopathological characteristics, 3) predictive biomarkers for course or prognosis, 4) response to therapies and 5) drug safety or toxicity (Perrin, 2014; Prabhakar, 2012).

Four types of animal models are used in preclinical research: 1) disease induction models, 2) xenograft animal models, 3) inbred strains, and 4) transgenic models (Prabhakar, 2012). The rodent stroke model of middle cerebral artery occlusion is a typical disease induction model. Xenografting or transplantation of organs or tissues from one species into another is often used in cancer research. "Humanized" mice are another example of xenograft models (see below). Inbred animals are genetically homogenous allowing investigation of pathobiology with small sample sizes (Prabhakar, 2012). Using methods of molecular biology specific genes are either deleted (knock-out), mutated or overexpressed in transgenic animals, mainly mice. Often these models are combined, e.g. disease induction models in transgenic mice are often used to investigate the contribution of specific genes in diseases.

Rodent models of cerebral ischemia are good examples of animal models that replicate human pathophysiology well (Astrup et al, 1977; Heiss, 2011). The ischemic penumbra is defined as the area surrounding the core of the ischemic lesion. While physiological cascades are compromised, this area of brain tissue can potentially be rescued by medical intervention. This concept was first described in animal models (Astrup et al., 
1977; Heiss, 2011) and has since been found to be relevant for human stroke pathophysiology (Dirnagl et al, 1999; Donnan et al, 2008; Mergenthaler et al, 2004; Mergenthaler \& Meisel, 2012). The same has been found true for the concept of strokeinduced immunodepression. While the pathophysiological concept has initially been described in animal models (Chamorro et al, 2012; Prass et al, 2003), clinical trials have been able to replicate this concept in human stroke pathophysiology (Chamorro et al., 2012; Harms et al, 2008; Mergenthaler \& Meisel, 2012), albeit therapeutic protocols making use of this concept are still under development (Mergenthaler \& Meisel, 2012).

Likewise, animal models of cancer, and in particular genetically engineered mouse models, have significantly contributed to the understanding of tumor biology and cancer pathophysiology. In particular advances in genetic engineering have allowed modeling the manifold genetic defects underlying many forms of cancer (Cheon \& Orsulic, 2011). Likewise, the concept that several mutations in the genome might be required for tumor development as well as prototypic oncogenes have been established by the use of mouse models (Cheon \& Orsulic, 2011). However, similar to the situation in stroke (Dirnagl \& Fisher, 2012) mouse models in preclinical cancer research have yet to prove their translational capacity (Cheon \& Orsulic, 2011).

\subsubsection{What is a good animal model for translational research?}

It is clear that there is no single ideal animal model of human disease conditions. Likewise, the design of preclinical experimental studies at present offers substantial room for improvement. While this topic has recently received significant attention, many of the proposed remedies for the "translational roadblock" have yet to prove themselves in translational studies and the design of clinical trials. Among others, considering the complex characteristics of the animal models as well as of the human disease state is essential when selecting an appropriate model for preclinical studies. Three aspects are often not 
considered in preclinical studies: the heterogeneous nature of disease, the presence of comorbidities, and appropriate outcome measures (Mergenthaler \& Meisel, 2012).

Several approaches to improve translation from animals to the clinic have been suggested. Before starting clinical trials preclinical investigations should be performed in multiple experimental setting involving different small and large animals modeling different disease states including the characterization of the optimal therapeutic window, optimal administration routes and schemes as well as dose-response curves (Xiong et al, 2013). Furthermore, preclinical studies need to reflect the clinical scenarios. Importantly, these include relevant treatment windows and outcome parameters. For example, drug administration at onset or even before injury, as performed in many preclinical studies investigating disease mechanisms is of minor relevance for therapy.

Most preclinical research in stroke or traumatic brain injury (TBI) suffers from shortterm studies demonstrating treatment effects 1 to 7 days after the event (Xiong et al., 2013). Investigations on long-term outcome weeks to months after injury are still scarce. On the contrary, primary endpoints of clinical phase III trials have to focus on relevant long-term outcome measures.

Disease modeling focused on pathophysiological research is invariable an oversimplification of the clinical situation. For example, stroke patients often suffer from a variety of other diseases such as hypertension, diabetes mellitus or chronic obstructive pulmonary disease, which are commonly not modeled. Beyond the comorbidities patients have before stroke onset, patients are often affected by several post-stroke complications, such as infection or depression, which are also usually either not modeled or not considered. The same holds true for other disease models such as TBI. Moreover, stroke patients receive a myriad of treatments including medication and general care such as nursing and physiotherapy, among others. Although stroke unit care is efficient without any doubt we do not know, which single pieces of treatment are of relevance. Nevertheless, modeling of care 
is probably one prerequisite in successful translation of treatment strategies of complex disorders such as stroke (Mergenthaler \& Meisel, 2012).

\subsection{Modeling comorbidities}

Most investigators disregard the fact that most patients are not young or middle-aged males without any comorbidities (Howells et al, 2010; Sena et al, 2010). One fundamental criticism of animal research is that most models do not consider age (Howells et al., 2010), which is one of the most relevant cofactors of outcome for most non-communicable disorders (Howells et al., 2010; Lozano et al, 2012). However, young to middle-aged inbred rodents of one gender and of homogeneous genetic backgrounds are typically used for preclinical animal studies. Ideally, preclinical animal studies should use animal populations of mixed gender, advanced age and with various comorbidities, such as diabetes mellitus, hyperlipidemia, hypertension, obesity or other risk factors which are relevant for the respective human disease. Such an approach would model the human etiology of most diseases more closely. In many cases, such models are readily available (Howells et al., 2010). In addition, experimental animal populations should be increasingly complex as a therapeutic intervention advances in the translational pipeline (Figure 1). The concept of establishing a framework as well as funding schemes to enable such preclinical randomized controlled trials ( $p R C T s$ ) has been suggested in many medical disciplines including cancer (Cheon \& Orsulic, 2011) and stroke (Bath et al, 2009; Dirnagl \& Fisher, 2012; Mergenthaler \& Meisel, 2012).

\subsection{Modeling care of patients}

Many successful therapeutic strategies rely on 'intensified care' of (critically ill) patients in the acute phase of the disease on dedicated and highly specialized hospital wards. Acute care is usually complex and committed to optimize physiological parameters. 
Including such a strategy in preclinical modeling would aid to better model clinical care of patients as well as its associated complications.

In cerebral ischemia, stroke units are prepared to treat the clinical condition as well as potential complications (Donnan et al., 2008). Infections have largely been neglected in preclinical stroke research (Meisel \& Meisel, 2011; Meisel et al, 2005), although they heavily influence stroke outcome (Mergenthaler \& Meisel, 2012; Westendorp et al, 2011). While preventive antibacterial treatment not only prevents infections, it also improves survival and neurological outcome after experimental stroke compared with placebo treatment (Meisel et al, 2004); recent phase Ilb trials have successfully proven this experimental concept (Chamorro et al, 2005; Harms et al., 2008; Schwarz et al, 2008) by demonstrating that prevention of infection is effective in stroke patients (van de Beek et al, 2009). Thus, basic research findings and preclinical modeling preceded the development of this new treatment approach (Mergenthaler \& Meisel, 2012).

A novel approach to preclinical research would include modeling the acute, subacute and chronic phase of disease. Clinical and empirical evidence indicate that intensified and specialized treatments are beneficial for long-term outcome. Thus, taking "care" of patients should be reflected in future preclinical trials. In summary, preclinical trials as the foundation for future clinical trials should include large and complex cohorts of animals, and include gender-mixed, aged animals from different strains, ideally with different comorbidities, and model care of (hospitalized) patients. Furthermore, complex long-term outcome analyses should be performed to evaluate the success of a novel therapeutic concept or pharmacological agent (Figure 1).

\subsubsection{What is the translational value of animal models?}

Recurrent failure to translate promising treatment strategies in animal models into the clinic has challenged the value of animal research for predicting the effectiveness of treatment strategies in humans. Thus, animal models of human disorders are more and more 
condemned, have been considered meaningless or at best as imprecise for the human setting, all medical areas employ models that have advantages or limitations. At least, animal models are used successfully to define basic pharmacokinetic properties as well as to investigate safety and toxicity issues (McGonigle \& Ruggeri, 2014).

One example for this approach is the following. The devastating neurodegenerative disorder amyotrophic lateral sclerosis (ALS) is characterized by a progressive degeneration of motor neurons leading to a generalized paralysis, respiratory insufficiency and death usually within 3 to 5 years. Stem cell transplantation has emerged as a promising approach for ALS patients. Rather than motor neuron replacement current approaches consider mesenchymal or neural stem cells as supporters for motor neurons delaying neurodegeneration. Although some ALS models suggest that stem cell-based approaches might delay motor neuron degeneration current strategy in the field is rather not proving efficacy than demonstrating safety in preclinical models aiming at quick "translation" to the clinical setting investigating efficacy in patients. The main argument for this approach is the rather poor understanding of the ALS pathobiology (Thomsen et al, 2014). However, whether or not this safety focused approach in translation is successful or not remains to be demonstrated.

Even preclinical studies aiming at toxicity analysis might fail in predicting safety for humans. For example, the immunomodulatory humanized agonistic anti-CD28 monoclonal antibody TGN1412, which was developed for autoimmune disorders such as multiple sclerosis or rheumatoid arthritis was tested successfully for safety in various animal models including mice. However, in the first in man (phase I) trial TGN1412 caused a severe systemic inflammatory response syndrome due to a "cytokine storm" resulting in a disastrous outcome with a multi organ failure for the study participants, despite the fact that the dose used was 500 times lower than the dose found to be safe in animal studies (Suntharalingam et al, 2006). 
Drug discovery begins with target identification and validation, proceeds with identification and development of candidate therapeutic agents. At each step of this process, which often requires more than 12 years, animal models are needed (Whiteside et al, 2013). However, only $15 \%$ of novel drugs successfully tested in animal models pass early clinical trials and approximately half of them surviving phase III becomes finally approved by the regulatory authorities for clinical practice (Ledford, 2011).

Extrapolation of preclinical findings into the clinical settings might also depend on the substances under investigation. For example, animal models mimicking airway susceptibility in different lung disorders have been demonstrated to be predictive for the human situation for anesthetic drugs like halothane, isoflurane, propofol and ketamine but not lidocaine, morphine or muscle relaxants. Among others, variability between species in different receptor distributions and drug affinities might account for the different predictability of the preclinical models (Habre \& Petak, 2013).

Animal models of human tumors are considered as indispensable for drug discovery and development. The commonly used ectopic and orthotopic xenografts models, primary human tumorgraft models, genetically engineered models, or various multi-stage carcinogeninduced models all have different strengths and weaknesses (Cheon \& Orsulic, 2011; Heyer et al, 2010). These models should be used as sophisticated biological tools at specific stages of drug development in a hierarchical manner of increasingly complex modelling (Figure 1) of the diversity of human cancers (Ruggeri et al, 2014).

One approach to test the predictive power of animal models is conducting reversetranslational studies investigating known effective treatment strategies of human disorders in appropriate animal models. Temozolamide is a good example of a successful forward and reverse translational approach for the treatment of glioblastoma. A systematic review and meta-analysis of temozolomide in animal models of glioblastoma predicted clinical efficacy. This treatment is effective in reducing tumor volume and improving survival clinically as well as in experimental models of malignant glioma. The reported efficacy for treatment has not 
significantly changed after publication (Hirst et al, 2013) of the seminal phase III temozolomide trial demonstrating efficacy in glioblastoma patients (Stupp et al, 2005), although evidence suggests a publication bias overemphasizing its therapeutic efficacy (Hirst et al., 2013).

Genetic mouse models of Huntington's disease (HD) should help to identify and prioritize the most promising treatment strategies to be tested in clinical trials (Menalled \& Brunner, 2014). Many neural circuits affected by Huntington disease are evolutionary conserved. More than a dozen genetic mouse models express a mutation similar to that responsible in HD with many variations in CAG length of the Huntington gene. These models mimic the human genetic insult with different phenotypic aspects of HD (Menalled \& Brunner, 2014)

Numerous transgenic or surgically induced pig models of neurodegenerative disorders have been established in order to develop cell-replacement strategies. Defining the optimal cell dose, immunosuppression protocols and testing new cell delivery devices were a prerequisite for designing human clinical trial protocols in neurodegenerative disorders such as ALS, stroke, spinal cord and traumatic brain injury, Huntington's disease, Alzheimer's disease and Parkinson's disease. In contrast to other animal models, fully or partially MHCmatched pig strains model the human situation, thereby better modelling host versus graft and graft versus host reactions of cell and tissue replacement strategies (Dolezalova et al, 2014).

In neuropathic pain research, the effect size of successful pain treatment is almost twice in animal models as in clinical trials. Correspondingly, the number needed to treat (NNT), which reflects the number of individuals that must be treated in order to see one successful treatment outcome, is almost half in animal compared to clinical pain trials. Among others, placebo effects in clinical trials, which are absent in animal research, are significant confounders. Effect sizes of at least $60 \%$ pain relief in animal models are required to predict clinical efficacy (Whiteside et al., 2013). 
Psychiatric disease is not directly translatable to animal models. For example, even transgenic mouse models of neuropsychiatric disorders cannot fully represent the broad spectrum of symptoms, including confusion or suicidal thoughts. However, these models serve to explore psychiatric disorders by unravelling disturbances of neural circuits underlying disease relevant phenotypes, in particular how environmental and (epi-)genetic factors interact to shape behavioral phenotype and predispositions to psychiatric disorders (Donaldson \& Hen, 2014). Traditionally in psychiatric animal models abnormal animal behavior was created, phenotypically resembling the aspects of mental disorders. Reverse translation using knowledge about the mechanisms of human disorders has been used to identify and develop animals that have the molecular and cellular abnormalities found in these diseases (Malkesman et al, 2009). For example, depression has been modeled in mice having point mutations in the mitochondrial DNA polymerase (Kasahara et al, 2006) and glutamate receptor 6 knock mice have a high face and predictive validity for mania (Shaltiel et al, 2008).

Lost in translation has become a very popular paraphrase for the obstacles encountered in translational research. Three reasons for the "Lost In Translation Problem" have been suggested. First, small differences in the models might lead to vast differences in the results, which has been attributed to the chaotic behavior of the models and termed the "butterfly effect". Second, the effect size is decreasing from biochemical models over cell and tissue cultures to animal experiments to human studies, which seems to be unexpected according to the "princess and the pea" story. Finally, the "two cultures" of preclinical and clinical research are different (Ergorul \& Levin, 2013; Mergenthaler \& Meisel, 2012).

\subsubsection{Remedies for failed translation. - Improving preclinical research 3.1.6.4.1. Improving models}

In order to improve the quality of translational biomedicine it has been suggested to make the process of preclinical research more like clinical research. Among them, applying 
similar rules used by regulatory agencies for clinical trial has been suggested also for preclinical studies. Using methods such as systematic reviews and meta-analyses have become more and more popular in animal research to identify robust treatment effects. Commonly accepted "futility" and "stopping" rules in clinical research become increasingly accepted in preclinical research. These approaches have been demonstrated to improve the predictive value of animal research (Perel et al, 2007).

An ideal animal model will meet all of the following 3 criteria: face validity, predictive validity and construct validity. Face validity refers to the phenomenological similarity between the model and its corresponding disorder. Predictive validity refers to the ability of the model to have comparable biomarkers and treatment responses as the human disorder. Construct validity reflects the degree to which a model measures what it claims to be measuring (Willner, 1986).

In order to improve construct validity it has been proposed that therapeutic interventions should be tested in animal models of CNS disorders under conditions of greater environmental enrichment. One limitation of current research is that most animal studies are performed under caging conditions with sedentary, unstimulated animals having unlimited access to food. Enriched environment stimulating sensory system, cognition and physical exercise have been demonstrated to affect outcome significantly (McOmish et al, 2014).

In order to improve translational power, the use of more humanized models has been suggested (Ergorul \& Levin, 2013). Immunodeficient mice that have been engrafted with human primary haematopoietic cells and tissues generating a functional human immune system in these mice are a well-established example of humanized mice. These models have been successfully used investigating infectious diseases, autoimmune disorders and tumors (Shultz et al, 2012).

Recent exciting findings in stem cell biology open the door to novel approaches in disease modeling using human model systems. Terminally differentiated human somatic 
cells may be reprogrammed to an induced pluripotent stem cell (hiPSC) state in order to then differentiate these cells into any cell type of interest (Lee \& Studer, 2010). These developments might revolutionize investigations of human disorders, in particular those affecting the CNS (Philips et al, 2014). Patient-derived hiPSCs can be differentiated in specific neuronal subpopulations, e.g. cortical neurons (Zhang et al, 2013) or striatal medium spiny neurons (Philips et al., 2014), which are affected in brains of patients suffering from Huntington's disease. Obviously, brain cells are usually not directly accessible as primary material, neither for study disease mechanisms nor for specific treatment. Furthermore, in recent years, organoid technologies have revolutionized experimental biomedical research (Schutgens \& Clevers, 2020). In the context of brain research, human brain organoids (Lancaster, 2020; Lancaster et al, 2013) provide for the first time a human model system with the prospect of studying developmental aspects and disease mechanisms in a brain-like model system and have thus far mostly been used for studying brain development and developmental disorders (Marton \& Pasca, 2020). Using hiPSC technology, specific cell differentiation, organoid technologies and refined genomic editing tools (Hendriks et al, 2020), correction of mutations are feasible and specific treatment is conceivable (Kaye \& Finkbeiner, 2013). Although it has been suggested that failure in clinical trial could have been predicted at least in some cases using human pluripotent stem cell-based model systems (Antonic et al, 2018), translational success using these models has yet to be established.

Finally, cell based models cannot reflect the complexity of an organism. For example, investigating systemic effects of local disease, such as post-stroke pneumonia, requires animal models (Prass et al., 2003) to complement mechanistic cellular modeling. Another example is the blood brain barrier (BBB), a highly selective permeability barrier separating the blood from the brain extracellular fluid. Although sophisticated in vitro models of BBB have been developed in the last decade, drug transport across the BBB and brain specific drug delivery strategies remain challenging for developing of successful treatment strategies (Bicker et al, 2014). Enzymes usually cannot pass the BBB. However, local enzyme replacement therapy in the brain by intrathecal application is a promising strategy for the 
treatment of patients with metabolic disorders caused by the absence or malfunction enzymes involved in cerebral metabolism. For example, repeated injections of a recombinant enzyme into the spinal fluid (intrathecal) corrects enzyme deficiency and normalizes lysosomal storage in a canine model of mucopolysaccharidosis (Dickson \& Chen, 2011).

\subsection{Improve rigor of preclinical studies}

The lack of reproducibility of preclinical studies and the failure of translation to the clinic have attracted attention in the last years (Howells et al, 2014; Ioannidis, 2005; Macleod et al, 2014; Perrin, 2014; Prinz et al., 2011). One important reason is the publication bias toward reporting positive results due to difficulties or missing incentives in publishing negative results (Dirnagl \& Lauritzen, 2010; Dwan et al, 2013). Moreover, experimental design (loannidis et al, 2014; Neumann et al, 2017), including statistics (Schlattmann \& Dirnagl, 2010), has been challenged as a quality problem in preclinical trials. For example, definition and declaration of statistical approaches and endpoint measures needs to be performed before preclinical trials are finally analyzed or even started (Dirnagl \& Lauritzen, 2011). Whereas clinical trial registries are widely accepted as good clinical research practice, preclinical trial registries are rather uncommon and may need to be established (Dirnagl, 2020). Thereby, post-hoc analyses generating hypotheses in an exploratory manner can be clearly distinguished from a primary hypothesis that has been tested in a confirmatory approach. A priori power calculations and sample size considerations, randomized assignment to groups and blinding for treatment groups are further important issues well established in clinical but rather not preclinical research (Button et al, 2013).

Finally, it has been suggested that bringing the rigor and quality of study design expected in clinical trials to preclinical trials will improve translational success (Dirnagl \& Fisher, 2012; loannidis et al., 2014; Macleod et al., 2014). This includes better knowledge about the drug and thorough target assessment before starting a preclinical trial (Emmerich et al, 2020). For example, pharmacokinetics might be different between mutants and wild- 
type mice (Menalled et al, 2010). Confirmation of research findings includes replication of preclinical research in independent laboratories (Figure 2). Using different models will increase robustness of the observed findings in treatment effects (Menalled \& Brunner, 2014).

Endpoint measures are of great importance in preclinical research as well as in clinical research and should therefore follow endpoints used in clinical research as close as possible. For example, Huntington's disease is not only characterized by motor symptoms but also by cognitive and psychiatric symptoms appearing years before the loss of motor control. These complaints often have a large impact on the quality of life. Although survival is an important outcome measure also in clinical trials, caution is required when translating preclinical into clinical findings. In contrast to animals even in preclinical research, survival in patients does not only depend on the specific intervention under investigation but also on general care as well as ethical and religious issues leading to end-of-life decisions.

Specific suggestions for improving the predictiveness of preclinical stroke research have been oriented on accepted standards of clinical research (Bath et al., 2009; Dirnagl, 2020; Macleod et al, 2009; Mergenthaler \& Meisel, 2012). In order to improve internal validity, good clinical research avoids any kind of bias, in particular selection bias (biased allocation to treatment groups), performance (biased care of treatment groups apart from intervention under study), assessment (biased rating due to knowledge of treatment assignment) and attrition (biased handling of protocol violation and loss in follow up).

Preclinical research in the final stages of translation into clinical trials should follow the guidelines of clinical research by: 1) improving internal validity by predefined inclusion/exclusion criteria and primary endpoint(s), randomization, blinding for treatment allocation and outcome assessment intention-to-treat analysis; 2) improving external validity by studying pathophysiology and treatment strategies in animals of both sexes, old age and with co-morbidities, disease-related appropriate dosing and treatment windows for the drug under investigation; 3) replicating pivotal findings; 4) publishing negative as well as positive 
results; focus on long-term functional outcome; use meta-analyses of pre-clinical studies; 5) establishing registries of preclinical studies and 6) international multicenter phase III preclinical trials (Dirnagl \& Endres, 2014; van der Worp et al, 2010). Moreover, preclinical trials need a standardized and "humanized" modelling of general as well as disease specific patient care (Mergenthaler \& Meisel, 2012).

\subsubsection{Summary}

In summary, many well-defined animal models for human disease are employed in modern preclinical and pathophysiology-driven research. However, the scientific community across all fields of modern biomedicine has become aware of weaknesses in current preclinical animal modeling. Here, we have outlined several strategies that have already been set into action to overcome the translational gap that is common to all current preclinical modeling of human disease. 


\subsubsection{References}

Antonic A, Dottori M, Macleod MR, Donnan GA, Howells DW. (2018) NXY-059, a Failed Stroke Neuroprotectant, Offers No Protection to Stem Cell-Derived Human Neurons. J Stroke Cerebrovasc Dis. 27 2158-2165.

Astrup J, Symon L, Branston NM, Lassen NA. (1977) Cortical evoked potential and extracellular $\mathrm{K}+$ and $\mathrm{H}+$ at critical levels of brain ischemia. Stroke; a journal of cerebral circulation. 8 51-57.

Bath PM, Macleod MR, Green AR. (2009) Emulating multicentre clinical stroke trials: a new paradigm for studying novel interventions in experimental models of stroke. International journal of stroke : official journal of the International Stroke Society. 4 471-479.

Bicker J, Alves G, Fortuna A, Falcao A. (2014) Blood-brain barrier models and their relevance for a successful development of CNS drug delivery systems: a review. European journal of pharmaceutics and biopharmaceutics : official journal of Arbeitsgemeinschaft fur Pharmazeutische Verfahrenstechnik eV. 87 409-432.

Button KS, loannidis JP, Mokrysz C, Nosek BA, Flint J, Robinson ES, Munafo MR. (2013) Power failure: why small sample size undermines the reliability of neuroscience. Nature reviews Neuroscience. 14 365-376.

Chamorro A, Horcajada JP, Obach V, Vargas M, Revilla M, Torres F, Cervera A, Planas AM, Mensa J. (2005) The Early Systemic Prophylaxis of Infection After Stroke study: a randomized clinical trial. Stroke; a journal of cerebral circulation. 36 1495-1500.

Chamorro A, Meisel A, Planas AM, Urra X, van de Beek D, Veltkamp R. (2012) The immunology of acute stroke. Nature reviews Neurology. 8 401-410.

Cheon DJ, Orsulic S. (2011) Mouse models of cancer. Annual review of pathology. 6 95-119.

Dickson PI, Chen AH. (2011) Intrathecal enzyme replacement therapy for mucopolysaccharidosis I: translating success in animal models to patients. Current pharmaceutical biotechnology. 12 946-955 
Dirnagl U, ladecola C, Moskowitz MA. (1999) Pathobiology of ischaemic stroke: an integrated view. Trends in neurosciences. 22 391-397.

Dirnagl U, Lauritzen M. (2010) Fighting publication bias: introducing the Negative Results section. Journal of cerebral blood flow and metabolism : official journal of the International Society of Cerebral Blood Flow and Metabolism. 30 1263-1264.

Dirnagl U, Lauritzen M. (2011) Improving the quality of biomedical research: guidelines for reporting experiments involving animals. Journal of cerebral blood flow and metabolism : official journal of the International Society of Cerebral Blood Flow and Metabolism. 31 989-990.

Dirnagl U, Fisher M. (2012) International, multicenter randomized preclinical trials in translational stroke research: It's time to act. Journal of cerebral blood flow and metabolism : official journal of the International Society of Cerebral Blood Flow and Metabolism. 32 933-935.

Dirnagl U, Endres M. (2014) Found in translation: preclinical stroke research predicts human pathophysiology, clinical phenotypes, and therapeutic outcomes. Stroke; a journal of cerebral circulation. 45 1510-1518.

Dirnagl U. (2020) Preregistration of exploratory research: Learning from the golden age of discovery. PLoS biology. 18 e3000690.

Dolezalova D, Hruska-Plochan M, Bjarkam CR, Sorensen JC, Cunningham M, Weingarten D, Ciacci JD, Juhas S, Juhasova J, Motlik J, Hefferan MP, Hazel T, Johe K, Carromeu C, Muotri A, Bui J, Strnadel J, Marsala M. (2014) Pig models of neurodegenerative disorders: Utilization in cell replacement-based preclinical safety and efficacy studies. The Journal of comparative neurology. 522 2784-2801.

Donaldson ZR, Hen R. (2014) From Psychiatric Disorders to Animal Models: A Bidirectional and Dimensional Approach. Biological psychiatry 10.1016/j.biopsych.2014.02.004

Donnan GA, Fisher M, Macleod M, Davis SM. (2008) Stroke. Lancet. 371 1612-1623. 
Dwan K, Gamble C, Williamson PR, Kirkham JJ, Reporting Bias G. (2013) Systematic review of the empirical evidence of study publication bias and outcome reporting bias - an updated review. PloS one. 8 e66844.

Emmerich $\mathrm{CH}$, Gamboa LM, Hofmann MCJ, Bonin-Andresen M, Arbach O, Schendel P, Gerlach B, Hempel K, Bespalov A, Dirnagl U, Parnham MJ. (2020) Improving target assessment in biomedical research: the GOT-IT recommendations. Nature reviews Drug discovery 10.1038/s41573-020-0087-3

Ergorul C, Levin LA. (2013) Solving the lost in translation problem: improving the effectiveness of translational research. Current opinion in pharmacology. 13 108-114.

Habre W, Petak F. (2013) Anaesthesia management of patients with airway susceptibilities: what have we learnt from animal models? European journal of anaesthesiology. 30 519-528.

Harms H, Prass K, Meisel C, Klehmet J, Rogge W, Drenckhahn C, Gohler J, Bereswill S, Gobel U, Wernecke KD, Wolf T, Arnold G, Halle E, Volk HD, Dirnagl U, Meisel A. (2008) Preventive antibacterial therapy in acute ischemic stroke: a randomized controlled trial. PloS one. 3 e2158.

Heiss WD. (2011) The ischemic penumbra: correlates in imaging and implications for treatment of ischemic stroke. The Johann Jacob Wepfer award 2011. Cerebrovasc Dis. 32 307-320.

Hendriks D, Clevers H, Artegiani B. (2020) CRISPR-Cas Tools and Their Application in Genetic Engineering of Human Stem Cells and Organoids. Cell Stem Cell. 27 705731.

Heyer J, Kwong LN, Lowe SW, Chin L. (2010) Non-germline genetically engineered mouse models for translational cancer research. Nature reviews Cancer. 10 470-480.

Hirst TC, Vesterinen HM, Sena ES, Egan KJ, Macleod MR, Whittle IR. (2013) Systematic review and meta-analysis of temozolomide in animal models of glioma: was clinical efficacy predicted? British journal of cancer. 108 64-71. 
Howells DW, Porritt MJ, Rewell SS, O'Collins V, Sena ES, van der Worp HB, Traystman RJ, Macleod MR. (2010) Different strokes for different folks: the rich diversity of animal models of focal cerebral ischemia. Journal of cerebral blood flow and metabolism : official journal of the International Society of Cerebral Blood Flow and Metabolism. 30 $1412-1431$.

Howells DW, Sena ES, Macleod MR. (2014) Bringing rigour to translational medicine. Nature reviews Neurology. 10 37-43.

loannidis JP. (2005) Why most published research findings are false. PLoS medicine. 2 e124.

Ioannidis JP, Greenland S, Hlatky MA, Khoury MJ, Macleod MR, Moher D, Schulz KF, Tibshirani R. (2014) Increasing value and reducing waste in research design, conduct, and analysis. Lancet. 383 166-175.

Kasahara T, Kubota M, Miyauchi T, Noda Y, Mouri A, Nabeshima T, Kato T. (2006) Mice with neuron-specific accumulation of mitochondrial DNA mutations show mood disorderlike phenotypes. Molecular psychiatry. 11 577-593, 523.

Kaye JA, Finkbeiner S. (2013) Modeling Huntington's disease with induced pluripotent stem cells. Molecular and cellular neurosciences. 56 50-64.

Lancaster MA, Renner M, Martin CA, Wenzel D, Bicknell LS, Hurles ME, Homfray T, Penninger JM, Jackson AP, Knoblich JA. (2013) Cerebral organoids model human brain development and microcephaly. Nature. 501 373-379.

Lancaster MA. (2020) Brain organoids: A new frontier of human neuroscience research. Semin Cell Dev Biol 10.1016/j.semcdb.2020.10.011

Ledford H. (2011) Translational research: 4 ways to fix the clinical trial. Nature. 477 526-528.

Lee G, Studer L. (2010) Induced pluripotent stem cell technology for the study of human disease. Nature methods. 7 25-27.

Lozano R, Naghavi M, Foreman K, Lim S, Shibuya K, Aboyans V, Abraham J, Adair T, Aggarwal R, Ahn SY, Alvarado M, Anderson HR, Anderson LM, Andrews KG, Atkinson C, Baddour LM, Barker-Collo S, Bartels DH, Bell ML, Benjamin EJ, Bennett 
D, Bhalla K, Bikbov B, Bin Abdulhak A, Birbeck G, Blyth F, Bolliger I, Boufous S, Bucello C, Burch M, Burney P, Carapetis J, Chen H, Chou D, Chugh SS, Coffeng LE, Colan SD, Colquhoun S, Colson KE, Condon J, Connor MD, Cooper LT, Corriere M, Cortinovis M, de Vaccaro KC, Couser W, Cowie BC, Criqui MH, Cross M, Dabhadkar KC, Dahodwala N, De Leo D, Degenhardt L, Delossantos A, Denenberg J, Des Jarlais DC, Dharmaratne SD, Dorsey ER, Driscoll T, Duber H, Ebel B, Erwin PJ, Espindola P, Ezzati M, Feigin V, Flaxman AD, Forouzanfar MH, Fowkes FG, Franklin R, Fransen M, Freeman MK, Gabriel SE, Gakidou E, Gaspari F, Gillum RF, Gonzalez-Medina D, Halasa YA, Haring D, Harrison JE, Havmoeller R, Hay RJ, Hoen B, Hotez PJ, Hoy D, Jacobsen KH, James SL, Jasrasaria R, Jayaraman S, Johns N, Karthikeyan G, Kassebaum N, Keren A, Khoo JP, Knowlton LM, Kobusingye O, Koranteng A, Krishnamurthi R, Lipnick M, Lipshultz SE, Ohno SL, Mabweijano J, Maclntyre MF, Mallinger L, March L, Marks GB, Marks R, Matsumori A, Matzopoulos R, Mayosi BM, McAnulty JH, McDermott MM, McGrath J, Mensah GA, Merriman TR, Michaud C, Miller M, Miller TR, Mock C, Mocumbi AO, Mokdad AA, Moran A, Mulholland K, Nair MN, Naldi L, Narayan KM, Nasseri K, Norman P, O'Donnell M, Omer SB, Ortblad K, Osborne R, Ozgediz D, Pahari B, Pandian JD, Rivero AP, Padilla RP, Perez-Ruiz F, Perico N, Phillips D, Pierce K, Pope CA, 3rd, Porrini E, Pourmalek F, Raju M, Ranganathan D, Rehm JT, Rein DB, Remuzzi G, Rivara FP, Roberts T, De Leon FR, Rosenfeld LC, Rushton L, Sacco RL, Salomon JA, Sampson U, Sanman E, Schwebel DC, Segui-Gomez M, Shepard DS, Singh D, Singleton J, Sliwa K, Smith E, Steer A, Taylor JA, Thomas B, Tleyjeh IM, Towbin JA, Truelsen T, Undurraga EA, Venketasubramanian N, Vijayakumar L, Vos T, Wagner GR, Wang M, Wang W, Watt K, Weinstock MA, Weintraub R, Wilkinson JD, Woolf AD, Wulf S, Yeh PH, Yip P, Zabetian A, Zheng ZJ, Lopez AD, Murray CJ, AlMazroa MA, Memish ZA. (2012) Global and regional mortality from 235 causes of death for 20 age groups in 1990 and 2010: a systematic analysis for the Global Burden of Disease Study 2010. Lancet. 380 2095-2128. 
Macleod MR, Fisher M, O'Collins V, Sena ES, Dirnagl U, Bath PM, Buchan A, van der Worp HB, Traystman R, Minematsu K, Donnan GA, Howells DW. (2009) Good laboratory practice: preventing introduction of bias at the bench. Stroke; a journal of cerebral circulation. 40 e50-52.

Macleod MR, Michie S, Roberts I, Dirnagl U, Chalmers I, loannidis JP, Al-Shahi Salman R, Chan AW, Glasziou P. (2014) Biomedical research: increasing value, reducing waste. Lancet. 383 101-104.

Malkesman O, Austin DR, Chen G, Manji HK. (2009) Reverse translational strategies for developing animal models of bipolar disorder. Disease models \& mechanisms. 2238 245

Marton RM, Pasca SP. (2020) Organoid and Assembloid Technologies for Investigating Cellular Crosstalk in Human Brain Development and Disease. Trends Cell Biol. 30 133-143.

McGonigle P, Ruggeri B. (2014) Animal models of human disease: challenges in enabling translation. Biochemical pharmacology. 87 162-171.

McOmish CE, Burrows EL, Hannan AJ. (2014) Identifying novel interventional strategies for psychiatric disorders: integrating genomics, 'enviromics' and gene-environment interactions in valid preclinical models. British journal of pharmacology. $1714719-$ 4728.

Meisel C, Prass K, Braun J, Victorov I, Wolf T, Megow D, Halle E, Volk HD, Dirnagl U, Meisel A. (2004) Preventive antibacterial treatment improves the general medical and neurological outcome in a mouse model of stroke. Stroke; a journal of cerebral circulation. 35 2-6.

Meisel C, Schwab JM, Prass K, Meisel A, Dirnagl U. (2005) Central nervous system injuryinduced immune deficiency syndrome. Nature reviews Neuroscience. 6 775-786.

Meisel C, Meisel A. (2011) Suppressing immunosuppression after stroke. The New England journal of medicine. 365 2134-2136. 
Menalled L, Brunner D. (2014) Animal models of Huntington's disease for translation to the clinic: Best practices. Movement disorders : official journal of the Movement Disorder Society. 29 1375-1390.

Menalled LB, Patry M, Ragland N, Lowden PA, Goodman J, Minnich J, Zahasky B, Park L, Leeds J, Howland D, Signer E, Tobin AJ, Brunner D. (2010) Comprehensive behavioral testing in the R6/2 mouse model of Huntington's disease shows no benefit from CoQ10 or minocycline. PloS one. 5 e9793.

Mergenthaler P, Dirnagl U, Meisel A. (2004) Pathophysiology of stroke: lessons from animal models. Metabolic brain disease. 19 151-167.

Mergenthaler P, Meisel A. (2012) Do stroke models model stroke? Disease models \& mechanisms. 5 718-725.

Neumann K, Grittner U, Piper SK, Rex A, Florez-Vargas O, Karystianis G, Schneider A, Wellwood I, Siegerink B, loannidis JP, Kimmelman J, Dirnagl U. (2017) Increasing efficiency of preclinical research by group sequential designs. PLoS biology. 15 e2001307.

O'Collins VE, Macleod MR, Donnan GA, Horky LL, van der Worp BH, Howells DW. (2006) 1,026 experimental treatments in acute stroke. Annals of neurology. 59 467-477. Perel P, Roberts I, Sena E, Wheble P, Briscoe C, Sandercock P, Macleod M, Mignini LE, Jayaram P, Khan KS. (2007) Comparison of treatment effects between animal experiments and clinical trials: systematic review. Bmj. 334197.

Perrin S. (2014) Preclinical research: Make mouse studies work. Nature. 507 423-425.

Philips T, Rothstein JD, Pouladi MA. (2014) Preclinical models: Needed in translation? A Pro/Con debate. Movement disorders : official journal of the Movement Disorder Society. 29 1391-1396.

Prabhakar S. (2012) Translational research challenges: finding the right animal models. Journal of investigative medicine : the official publication of the American Federation for Clinical Research. 60 1141-1146. 
Prass K, Meisel C, Hoflich C, Braun J, Halle E, Wolf T, Ruscher K, Victorov IV, Priller J, Dirnagl U, Volk HD, Meisel A. (2003) Stroke-induced immunodeficiency promotes spontaneous bacterial infections and is mediated by sympathetic activation reversal by poststroke $T$ helper cell type 1 -like immunostimulation. The Journal of experimental medicine. 198 725-736.

Prinz F, Schlange T, Asadullah K. (2011) Believe it or not: how much can we rely on published data on potential drug targets? Nature reviews Drug discovery. 10712.

Ruggeri BA, Camp F, Miknyoczki S. (2014) Animal models of disease: pre-clinical animal models of cancer and their applications and utility in drug discovery. Biochemical pharmacology. 87 150-161.

Schlattmann P, Dirnagl U. (2010) Statistics in experimental cerebrovascular researchcomparison of two groups with a continuous outcome variable. Journal of cerebral blood flow and metabolism : official journal of the International Society of Cerebral Blood Flow and Metabolism. 30 474-479.

Schutgens F, Clevers H. (2020) Human Organoids: Tools for Understanding Biology and Treating Diseases. Annual review of pathology. 15 211-234.

Schwarz S, Al-Shajlawi F, Sick C, Meairs S, Hennerici MG. (2008) Effects of prophylactic antibiotic therapy with mezlocillin plus sulbactam on the incidence and height of fever after severe acute ischemic stroke: the Mannheim infection in stroke study (MISS). Stroke; a journal of cerebral circulation. 39 1220-1227.

Sena ES, van der Worp HB, Bath PM, Howells DW, Macleod MR. (2010) Publication bias in reports of animal stroke studies leads to major overstatement of efficacy. PLoS biology. 8 e1000344.

Shaltiel G, Maeng S, Malkesman O, Pearson B, Schloesser RJ, Tragon T, Rogawski M, Gasior M, Luckenbaugh D, Chen G, Manji HK. (2008) Evidence for the involvement of the kainate receptor subunit GluR6 (GRIK2) in mediating behavioral displays related to behavioral symptoms of mania. Molecular psychiatry. 13 858-872. 
Shultz LD, Brehm MA, Garcia-Martinez JV, Greiner DL. (2012) Humanized mice for immune system investigation: progress, promise and challenges. Nature reviews Immunology. $12786-798$.

Stupp R, Mason WP, van den Bent MJ, Weller M, Fisher B, Taphoorn MJ, Belanger K, Brandes AA, Marosi C, Bogdahn U, Curschmann J, Janzer RC, Ludwin SK, Gorlia T, Allgeier A, Lacombe D, Cairncross JG, Eisenhauer E, Mirimanoff RO, European Organisation for R, Treatment of Cancer Brain T, Radiotherapy G, National Cancer Institute of Canada Clinical Trials G. (2005) Radiotherapy plus concomitant and adjuvant temozolomide for glioblastoma. The New England journal of medicine. 352 987-996.

Suntharalingam G, Perry MR, Ward S, Brett SJ, Castello-Cortes A, Brunner MD, Panoskaltsis N. (2006) Cytokine storm in a phase 1 trial of the anti-CD28 monoclonal antibody TGN1412. The New England journal of medicine. 355 1018-1028.

Thomsen GM, Gowing G, Svendsen S, Svendsen CN. (2014) The past, present and future of stem cell clinical trials for ALS. Experimental neurology 10.1016/j.expneurol.2014.02.021

van de Beek D, Wijdicks EF, Vermeij FH, de Haan RJ, Prins JM, Spanjaard L, Dippel DW, Nederkoorn PJ. (2009) Preventive antibiotics for infections in acute stroke: a systematic review and meta-analysis. Archives of neurology. 66 1076-1081. van der Worp HB, Howells DW, Sena ES, Porritt MJ, Rewell S, O'Collins V, Macleod MR. (2010) Can animal models of disease reliably inform human studies? PLoS medicine. 7 e 1000245.

Westendorp WF, Nederkoorn PJ, Vermeij JD, Dijkgraaf MG, van de Beek D. (2011) Poststroke infection: a systematic review and meta-analysis. BMC neurology. 11110. Whiteside GT, Pomonis JD, Kennedy JD. (2013) An industry perspective on the role and utility of animal models of pain in drug discovery. Neuroscience letters. 557 Pt A 6572. 
Willner P. (1986) Validation criteria for animal models of human mental disorders: learned helplessness as a paradigm case. Progress in neuro-psychopharmacology \& biological psychiatry. 10 677-690.

Xiong Y, Mahmood A, Chopp M. (2013) Animal models of traumatic brain injury. Nature reviews Neuroscience. 14 128-142.

Zhang Y, Pak C, Han Y, Ahlenius H, Zhang Z, Chanda S, Marro S, Patzke C, Acuna C, Covy J, Xu W, Yang N, Danko T, Chen L, Wernig M, Sudhof TC. (2013) Rapid single-step induction of functional neurons from human pluripotent stem cells. Neuron. 78 785798. 


\section{Figures}

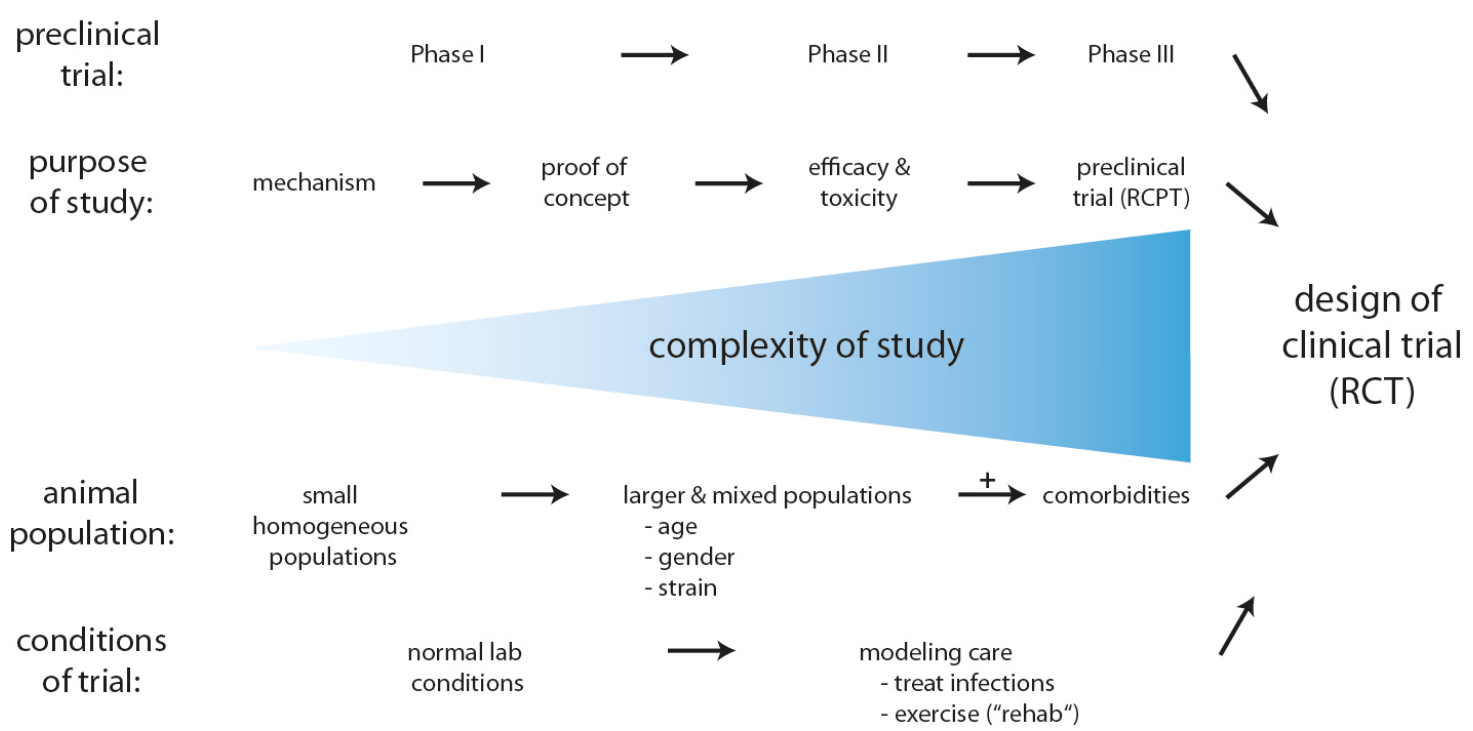

Figure 1. The preclinical trial phases of translational research. As therapeutic agents or concepts advance in development, the experimental setting increases in complexity. It ranges from small cohorts to investigate novel mechanisms to large mixed populations with (multiple) comorbidities and additional modeling of stroke care. The final stage of preclinical development is the conduct of a randomized-controlled preclinical trial (RCPT), ideally in a stroke unit setting. Randomized clinical trials (RCT) commence after this process has been completed and is based on evidence gained in preclinical testing. Reproduced with permission from: Mergenthaler P \& Meisel A. (2012). Do stroke models model stroke? Dis Model Mech. 5, 718-725. 

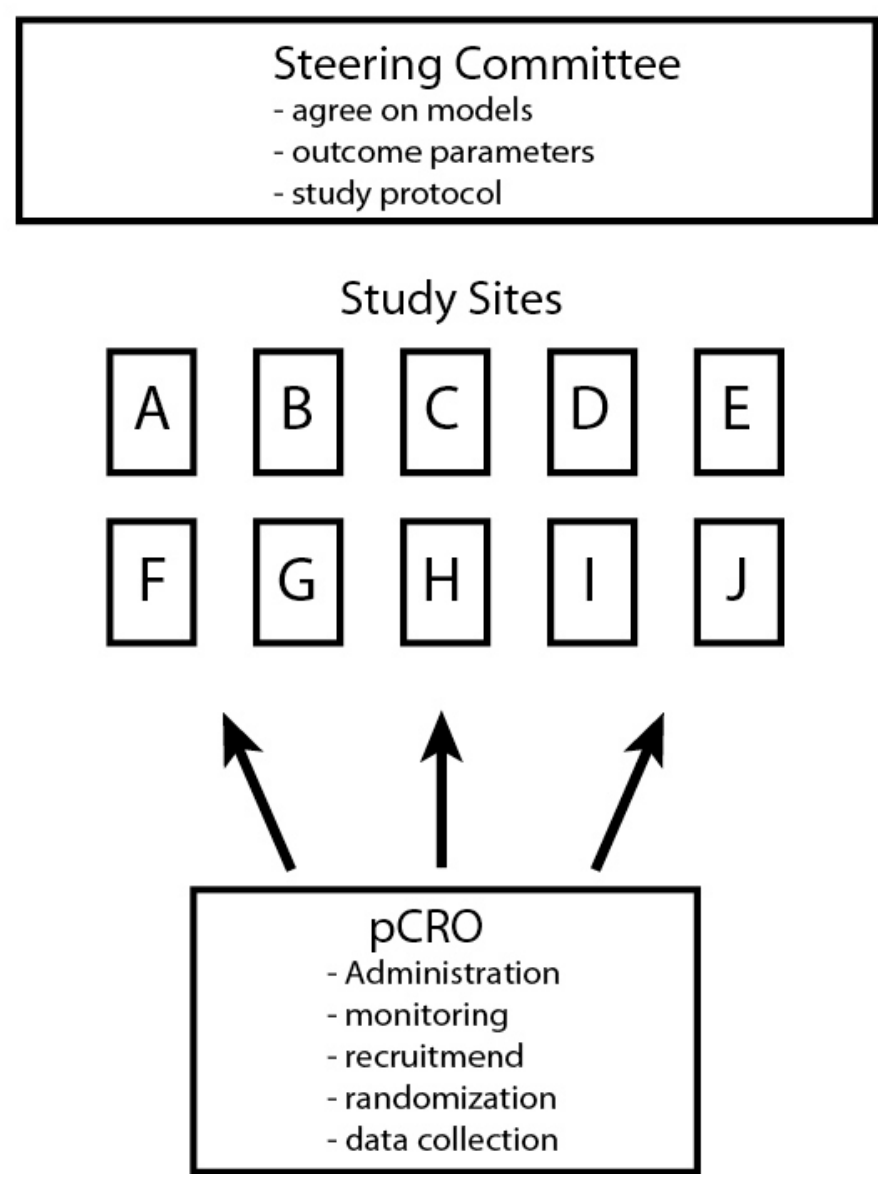

Figure 2. Modeled after randomized controlled clinical trials (RCT), the final stage of preclinical testing is to conduct a randomized controlled preclinical trial (RCPT). A steering committee agrees on the intervention to be tested and all related aspects (e.g. models, outcome parameters, etc.). All administrative matters are centrally organized by a preclinical research organization ( $\mathrm{pCRO}$ ) and include objective criteria for the recruitment of study sites, the modes of randomization, collection of the data from the study sites and central monitoring of all aspects of the trial. Ideally, all study sites are capable of performing the same experiments (i.e. they have access to the same models and equipment). All aspects of the RCPT are monitored by an independent organization. Reproduced with permission from: Mergenthaler P \& Meisel A. (2012). Do stroke models model stroke? Dis Model Mech. 5, 718-725. 